\title{
Pharmacist's interventions in reducing the incidences of drug related problems in any practice setting
}

\author{
*Irsa Jamal ${ }^{1}$, Fatima Amin 1 , Anam Jamal ${ }^{2}$ and Amna Saeed ${ }^{1}$ \\ ${ }^{1}$ Institute of Pharmacy, Lahore College for Women University, Jail Road, Lahore, Pakistan (54000) \\ ${ }^{2}$ Department of Chemistry, Lahore College for Women University, Jail Road, Lahore, Pakistan (54000)
}

\begin{abstract}
A drug-related problem is an event or circumstance involving drug treatment that actually or potentially interferes with the patient's experiencing an optimum outcome of medical care. The pharmacists can play key role in reducing the incidences of DRPs by making appropriate intervention at each stage and by working with other healthcare professionals. The aim of this study was to observe the Pharmacist clinical knowledge about DRPs and the extent to which they participate in reducing the incidences of DRPs. A questionnaire based survey was conducted among hundred pharmacists selected by random sampling in different health care settings from Lahore district. According to data collected it was found that $100 \%$ of Pharmacists had knowledge about DRPs and Pharmaceutical care. Different types of DRPs were identified by Pharmacists but only $41 \%$ of Pharmacists reported these DRPs and $37 \%$ of Pharmacists intervened to reduce the incidences of DRPs. Majority of the Pharmacists had knowledge about DRPs, other related terms and also about reporting but most of them did not actively participate to reduce incidences of DRPs because of lack of their acceptance by society and other health care professionals, lack of proper reporting system, lack of incentives and lack of time due to managerial job structure specially in case of retail pharmacy setup.
\end{abstract}

Key Words: Drug related problems, Pharmacist, interventions, adverse drug reactions, pharmaceutical care, clinical pharmacy.

\section{INTRODUCTION}

The knowledgeable health reporter for the Boston Globe, Betsy Lehman, died from an overdose during chemotherapy. Willie King had the wrong leg amputated. Ben Kolb was eight years old when he died during "minor" surgery due to a drug mix-up. These horrific cases that make the headlines are just the tip of the iceberg (Janet et al., 2000).

In the case of most diseases drug therapy will enhance health-related quality of life. However, inappropriate use of drugs may be harmful and could evoke new adverse symptoms (Hege, 2007), like birth defects, kidney failure, liver failure, hypertension, and death that occur with even well-known prescribed and/or over-the-counter drug use (Bren, 2001). This has been known for centuries but, it was first when the reports of aplastic anaemia following treatment with chloramphenicol (Hoffmann et al., 1950) and of birth defects after use of thalidomide (Katzenstein and Mellin, 1962), given to pregnant woman either by doctors or purchased at the local drugstore due to which over 10 thousand children were born with deformities (Anne, 2005) (Christine, 2013). Such events increased the interest in drug-related problems (DRPs) dramatically. Since then, research in this field had been intensified. As paradoxical consequence of these researches drug therapy had gradually become more complex, thus made it increasingly challenging to prescribe drugs appropriately (Hege, 2007).

Drug related problems are an essential term in the world of Pharmaceutical care. Other terms can be used for the same concept, such as medication errors, but this term is different from drug related problems. The errors refer to the mistakes in the process that could lead to problems.

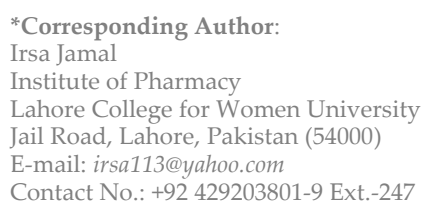

Drug related problems can originate when prescribing, dispensing or taking/administering medicines (Foppe, 2005).

Drug related problem (DRP) can be defined as: "an event or circumstance involving drug therapy that actually or potentially interferes with desired health outcomes" (definition PCNE, 1999).

In this perspective, a potential problem means a condition that may result in drug-related morbidity or death if no action is undertaken; an actual problem is manifested with signs and symptoms (Hege et al., 2007). It should be distinguished here that the use of the expression "problem" in the phrase "drug-related problem" is used to indicate a drug related event bendable to detection, treatment, or more aptly, prevention, and should not be interpreted in the common usage where it dimly gives the idea that "something (puzzle, paradox, perplexity) is wrong here (Linda et al., 1990).

DRPs can also be defined as "problems in the pharmacotherapy of the individual patient that actually or potentially interfere with desired health outcomes" (definition PCNE, 1999). The vital element of this definition is the effect of the problem on the health-end result of the pharmacotherapy. There is no drug-related problem if there is no probable influence (Foppe, 2005).

In 1990, Linda Strand wrote: “A Drug Related Problem (DRP) occurs when a patient experiences or is liable to experience either a disease or symptom having a definite or assumed association with drug therapy" (Linda et al., 1990).

Examples of medicine-related problems are adverse drug reaction, inappropriate use and poisoning (Antoine et al., 2000). Adverse drug reaction is defined as "an appreciably harmful or unpleasant reaction, consequential from an intervention associated to the use of a medicinal product, that prognosticate risk from future administration and warrants prevention or particular treatment, or 
modification of the dosage regimen, or withdrawal of the product" (Aronson, 2000).

A mean of categorizing drug-related problems (DRPs) is considered necessary to better focus the role of the pharmacist on the patient need and patient outcome (Linda et al., 1990). Keeping in account their characteristics and distinctions, all medicine-related problems can be classified in many ways. One way discriminate between appropriate and inappropriate drug use, dose related and dose unrelated problems, and types A ('drug actions'), B ('patient reactions') and C ('statistical') adverse effects (Antoine et al., 2000).

Charles and Linda (1990) categorized DRPs into following eight categories; untreated indications, improper drug selection, sub-therapeutic dosage, failure to receive drugs, over dosage, adverse drug reactions, drug interactions, drug use without indication.

Many ways of classifications are available to code drug related problems but all those classifications have not been tested for validity and reproducibility. Among classifications which are continuously tested is PCNE (Pharmaceutical Care Network Europe) classification. Its basic classification has 4 primary domains for problems, 8 primary domains for causes, 5 primary domains for Interventions and 4 primary domains for outcome of intervention (PCNE, 1999) [See Annexure II].

Classification of DRPs can serve as a cynosure for establishing a systematic process for pharmacists to put in appreciably to positive patient outcomes (Ulrika, 2012).

The US Department of Health and Human Services defines Clinical Pharmacy as:

"Functions performed by pharmacists on behalf of the patient to identify, resolve and prevent drug-related problems" (Richard, 1990). This definition emphasizes more on optimizing the drug therapy of individual patients.

A Clinical pharmacists can play a very important role by addressing the whole range of drug therapy in hospitals and, in general, the clinical pharmacy services have been reported to improve patient care by reducing inappropriate prescribing (Bird and Lipton, 1994) (Hanlon et al., 1996), improve disease management (Abbott et al., 1998) (Donovan et al., 2006), diminish adverse drug events (Cotugno et al., 2006), reduce length of stay, ADRs and mortality (Bond and Raehl, 2006) and give economic benefit (Allen et al., 2004). He may review drug-related problems in different settings: in hospital multidisciplinary teams, in nursing homes and in primary care. The pharmacist's role to the optimization of drug therapy may be assessed by ascertaining the number of drug-related problems addressed or prevented, or by evaluating the clinical outcomes for the patients (Hege and Kirsten, 2008).

The aim of the study was to identify and describe the magnitude and types of DRPs in patients, to estimate the extent to which pharmacist plays his role in reducing the incidences of DRPs and to identify the pharmacist behavior towards solving drug issues, their therapeutic advice and how this advice is dealt with.

\section{MATERIALS AND METHODS}

An observational study was conducted in different health care settings of Lahore district to observe Pharmacist Interventions in Reducing the Incidence of DRPs. A sample size of 100 Pharmacist working in retail and hospital pharmacies was selected by random convenient sampling while Pharmacists working in Pharmaceutical industries were excluded from the study. Data Collection form was designed which was filled during face to face interview with the Pharmacist.

Following aspects regarding DRPs in different Health Care settings were observed:

$>$ Knowledge of Pharmacist about DRPs, Pharmaceutical Care and ADR.

$>$ Magnitude and occurrence of types of DRPs.

$>$ Reporting of ADRs and other DRPs

> Pharmacist intervention in reducing the incidence of DRPs.

$>$ Significance of Pharmacist's interventions according to other healthcare professional.

\section{RESULTS AND DISCUSSION}

A drug-related problem is an event or circumstance involving drug treatment that actually or potentially interferes with the patient's experiencing an optimum outcome of medical care (Charles and Linda, 1990). However, inappropriate use of drugs may be harmful and could evoke new adverse symptoms which might also increase patient's duration of stay at hospital. So, it is important to observe the role pharmacists are playing in reducing the incidence of DRPs. Clinical pharmacists can effectively identify and prevent clinically significant drugrelated problems.

A questionnaire based survey was conducted among the pharmacist in different health care settings of Lahore district, to observe a pharmacist's clinical knowledge and his/her ability to detect and appropriately resolve DRPs.

Drug-related problems (DRPs) are associated with significant morbidity and mortality, with most DRPs thought to be preventable (Bindoff et al., 2012). Clinical pharmacists can detect and either prevent or resolve many of these DRPs. So it is important for the pharmacist to have sound knowledge about DRPs. All pharmacists of the study group knew about DRPs which was a good sign that pharmacists in Pakistan are now paying heed to this important topic.

Pharmaceutical care is a component of pharmacy practice that entails the direct interaction of the pharmacist with the patient for the purpose of caring the patient's medication-related needs (Carlyn et al., 2008). So, a pharmacists working in any practice must know about pharmaceutical care and its significance. All respondents to the survey had knowledge about Pharmaceutical care indicating that they considered this part of pharmacy practice as a significant one.

DRPs were categorized as; untreated indications, improper drug selection, sub-therapeutic dosage, failure to receive drugs, over dosage, adverse drug reactions, drug interactions, drug use without indication (Charles and Linda, 1990). Pharmacist interventions to reduce these DRPs were observed during the survey.

Health professionals play an important role in monitoring the safety of medicines by reporting any suspected adverse drug reactions (ADRs). As health professionals, pharmacists are likely to observe adverse reactions to medicines. When they submit a suspected ADR report, they contribute to the ongoing collection of information. This can help in reducing the future incidence of ADR (a DRP). Under study group $89 \%$ of Pharmacists knew about ADR reporting while $11 \%$ of Pharmacists were unaware of it. So, it is evident from result that majority of the pharmacists knew about ADR reporting. It was also observed that they knew about the ADR reporting forms which are used internationally (i.e., MedWatch forms and yellow card) but they did not know about the ADR 


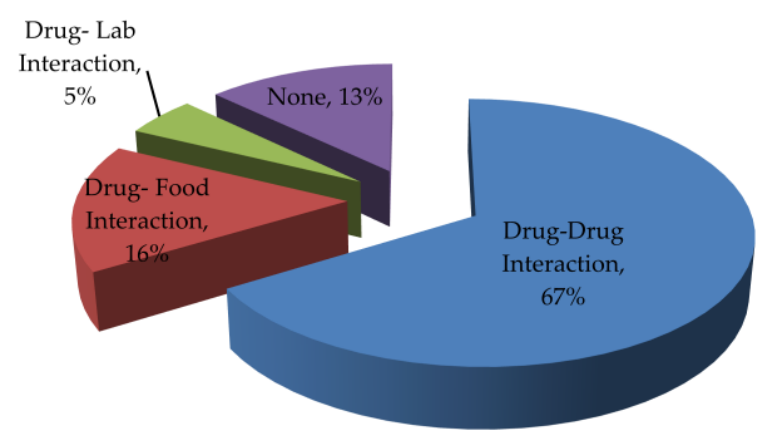

Figure 1: Pharmacists' observation of drug interaction.

reporting form made by Ministry of Health-Pakistan. A few pharmacists did not even know about ADR reporting which was probably because of the lack of ADR reporting system in Pakistani health care settings.

"Untreated indication" means that Patient has medical problem that requires drug therapy but is not receiving medication for that indication (Charles and Linda, 1990). It is one of the most commonly occurring DRP in our health care settings. $75 \%$ of Pharmacists identified untreated indications where as $25 \%$ of Pharmacists did not observe any. This shows that majority of the pharmacists were able to identify any untreated indication.

"Improper Drug Selection" is that, when a patient has medical problem that requires drug therapy but is taking the wrong medication (Charles and Linda, 1990). This DRP may also lead to patient's death. Proper drug selection is necessary for optimal medication management of a patient. Pharmacists are the healthcare professionals who with their thorough knowledge about drugs can help the prescribers for selecting appropriate drugs. $83 \%$ of Pharmacists in study group identified improper drug selection by the prescriber. This indicates that improper drug selection is frequent in health care settings of Pakistan. On the other hand this is also an indication that majority of the pharmacists are trying to identify such DRPs.

When a Patient's medical problem is being treated with an inadequate dose of the correct medication such dosage is called "Sub therapeutic Dosage" (Charles and Linda, 1990). By taking sub therapeutic dosage the patient do not show optimal therapeutic outcome. $75 \%$ of Pharmacists observed sub-therapeutic dosage prescribed by Physicians. This indicated that majority of the pharmacists had sound knowledge about proper dosages of drugs which enabled them to identify sub therapeutic dosages.

"Failure to receive drugs" is a DRP in which Patient has a medical problem that is the result of not receiving a drug (e.g., for pharmaceutical, psychological, sociological, or economic reasons) (Charles and Linda, 1990). A pharmacist working in a clinical setup can identify such cases and can make interventions to reduce their incidence. $70 \%$ of the Pharmacists observed the patients who failed to receive the drug while $30 \%$ did not do so. Most of the pharmacists who observed such patients mentioned that majority of the patients failed to receive drugs due to poor economic status.

An overdose means having too much of a correct drug (or combination of drugs) for body to be able to cope

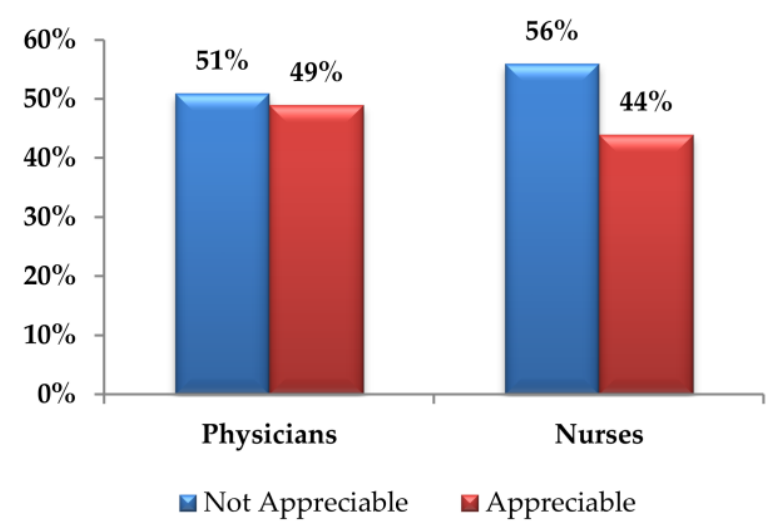

Figure 2: Appreciation of Pharmacists' intervention by Physicians and Nurses.

with (Charles and Linda, 1990). Pharmacists in all health care venues are likely to be exposed to cases of intentional and unintentional overdose, and should be able to recognize the risk factors and signs of overdose, as well as understand the strategies of pharmacologic management. Among study group $86 \%$ of Pharmacist vigilantly observed the cases of overdoses. They were well aware of the fact that they have important opportunity and responsibility in mitigating overdoses and ensuring that safety strategies for patients. Whereas $14 \%$ of the Pharmacist showed ignorant behavior in this regard but few mentioned that yet they did not experience such case.

ADR is any response to a drug which is noxious and unintended, and which occurs at doses normally used in man for prophylaxis, diagnosis, or therapy of disease, or for the modification of physiological function. Incidences of ADR have been consistently shown to increase in an exponential rather than a linear manner with the number of drugs taken (Fatimah et al., 2005). The most important concept for all practitioners to remember is that the only way to prevent ADRs is to look for them and learn how to properly monitor their occurrence. From the study, it was found that $81 \%$ of Pharmacists carefully observed the medical problems due to ADR. This shows that most of the Pharmacists were well aware of their significant role in preventing such problems where as $19 \%$ of Pharmacists were still ignorant of their responsibilities indicating that efforts should be made to make Pharmacist aware of their responsibilities.

A drug interaction is a situation in which a substance affects the activity of a drug when both are administered together (Arshad et al., 2011). Drug interactions may make drug less effective, cause unexpected side effects, or increase the action of a particular drug. Some drug interactions can even be harmful. In order to avoid such preventable DRPs Pharmacist should carefully observe such interaction. Among study group relatively more Pharmacist vigilantly observed such interactions. $67 \%$ of Pharmacists observed drug-drug interaction, $16 \%$ of Pharmacists observed drug-food interaction, 5\% of Pharmacists observed drug-lab interaction where as $13 \%$ of Pharmacists did not observe any interaction. Among these $13 \%$, few showed ignorant behavior and few had no chance to observe such cases (figure 1).

An indication is a valid reason to use a certain test, medication, procedure, or surgery. Now days it a common practice that Physicians are prescribing drugs to 
Table 1: Pharmacist's observations and interventions.

\begin{tabular}{|c|c|c|c|}
\hline $\begin{array}{l}\text { Sl. } \\
\text { No. }\end{array}$ & Statements & $\begin{array}{l}\text { YES } \\
(\%)\end{array}$ & $\begin{array}{l}\text { NO } \\
(\%)\end{array}$ \\
\hline 1. & $\begin{array}{l}\text { Knowledge about DRPs (Drug related } \\
\text { Problem). }\end{array}$ & 100 & 0 \\
\hline 2. & Knowledge about Pharmaceutical Care & 100 & 0 \\
\hline 3. & $\begin{array}{l}\text { Knowledge about ADR (Adverse Drug } \\
\text { Reaction) reporting }\end{array}$ & 89 & 11 \\
\hline 4. & $\begin{array}{l}\text { "Untreated indication" identified by Pharma- } \\
\text { cist }\end{array}$ & 75 & 25 \\
\hline 5. & $\begin{array}{l}\text { "Improper drug selection" noticed by the } \\
\text { Pharmacist }\end{array}$ & 83 & 17 \\
\hline 6. & $\begin{array}{l}\text { "Sub therapeutic dosage" observed by } \\
\text { Pharmacist }\end{array}$ & 75 & 25 \\
\hline 7. & $\begin{array}{l}\text { Observation of the case in which the patient } \\
\text { "failed to receive the drug" by Pharmacist }\end{array}$ & 70 & 30 \\
\hline 8. & $\begin{array}{l}\text { Any case of "over dosage" observed by } \\
\text { Pharmacist }\end{array}$ & 86 & 14 \\
\hline 9. & $\begin{array}{l}\text { Observation of any medical problem that was } \\
\text { a result of an ADR by Pharmacist }\end{array}$ & 81 & 19 \\
\hline 10. & $\begin{array}{l}\text { Observation of any case of drug use without } \\
\text { valid indication by Pharmacist }\end{array}$ & 78 & 22 \\
\hline 11. & Reporting of DRPs & 41 & 59 \\
\hline 12. & $\begin{array}{l}\text { Collaboration of Pharmacist with physicians } \\
\text { or other healthcare providers at particular } \\
\text { practice setting }\end{array}$ & 48 & 52 \\
\hline 13. & $\begin{array}{l}\text { Intervention to reduce incidence of DRPs by } \\
\text { Pharmacist }\end{array}$ & 37 & 63 \\
\hline 14. & $\begin{array}{l}\text { Acceptance of interventions by other health } \\
\text { care providers }\end{array}$ & 27 & 73 \\
\hline
\end{tabular}

patients for no valid indication just to fill the prescription for patient satisfaction but sometimes it is by mistake. Use of drug for invalid indication may lead to many adverse consequences in long or short run. Pharmacist should play a significant role to avoid invalid use by carefully monitoring the prescriptions. Among study group $78 \%$ of Pharmacists observed use of drug without valid indication. But only few intervened to do correction.

The most important function of spontaneous reporting systems is the early identification of signals (Grootheest and Harmark, 2008). Reporting is dependent on the initiative and motivation of the reporters. This leads to underreporting compared with actual incidence of DRPs (Chris et al., 2013). 41\% of Pharmacists actively reported DRPs where as 59\% of Pharmacists did not participate actively. Reporting was made to Physicians by Pharmacists in Community settings mostly through telephonic contact. Pharmacists in hospital setting
Table 2: Interventions made by Pharmacist, NOT ACCEPTED.

\begin{tabular}{ll}
\hline \multicolumn{1}{c}{ Interventions } & \multicolumn{1}{c}{ Acceptance } \\
\hline $\begin{array}{l}\text { Mostly potentiating effect had been } \\
\text { observed, and intervened. }\end{array}$ & $\begin{array}{l}\text { No } \\
\text { Reason: Patient blindly } \\
\text { trusts Prescriber }\end{array}$ \\
$\begin{array}{l}\text { Interventions were made to avoid } \\
\text { No }\end{array}$ \\
unindicated use of drug, like & $\begin{array}{l}\text { Reason: Prescriber in not } \\
\text { ready to compromise his }\end{array}$ \\
URI. & $\begin{array}{l}\text { authority. } \\
\text { Tried to compensate that drug or } \\
\text { problem with other alternative that }\end{array}$ \\
is safer. & $\begin{array}{l}\text { Reason: Patient was not } \\
\text { satisfied }\end{array}$ \\
\hline
\end{tabular}

reported to Physicians as well as to respective hospital committee made for this purpose or via online intervention form/patient care plan viewable to the concerned physician \& consultant, where applicable. Among $29 \%$ of Pharmacist few reported that their ignorant behavior was because of non-cooperative attitude of Physicians and absence of proper reporting system in practice.

Teamwork, communication and collaboration between health professionals are important for the safe and effective delivery of health care. There are evidences that greater collaboration between general practitioners and pharmacists can improve patient care (Debbie, 2010). From collected data it was found that $48 \%$ of Pharmacists worked in collaboration with other healthcare providers in their practice setting while $52 \%$ of Pharmacist remained reluctant in this aspect because according to them most Physicians do not want to work in collaboration with Pharmacists.

The role of pharmacists is expanding in primary care. The traditional relationship between the doctor as prescriber, and pharmacist as dispenser, is no longer appropriate to ensure safety, effectiveness and adherence to therapy. Pharmacists need to pay more attention to patient-centered, outcomes-focused care to optimize the safe and effective use of medicines (Debbie, 2010). 37\% of Pharmacists actively participated and intervened to reduce the incidences of DRPs, most of the DRPs in which pharmacist intervened were related to dose, dosage regimen, duration, dosage form, drug interaction. Only $27 \%$ of Physicians accepted the interventions by Pharmacists where as $73 \%$ of Physicians ignored these interventions and because of this ignorant behavior of Physicians 63\% of Pharmacists remained reluctant in this regard because they believed that interventions made by them are not going to be accepted and patients blindly follow their prescribers (table 1-3).

Table 3: Interventions made by Pharmacist, ACCEPTED.

\begin{tabular}{|c|c|}
\hline Interventions & Acceptance \\
\hline $\begin{array}{r}\text { Guided the patient about the medicine with which patient had allergy and switched } \\
\text { to alternative medicine. }\end{array}$ & $\begin{array}{l}\text { Yes } \\
\text { Reason: Patient was convinced and switched to } \\
\text { alternative medicine as it was beneficial for him }\end{array}$ \\
\hline $\begin{array}{l}\text { Polypharmacy regarding administration of multivitamins. } \\
\text { Co-administration of Lexotanil and Lorazepam at once. }\end{array}$ & Yes \\
\hline $\begin{array}{r}\text { Reduced potency of erythromycin } 500 \mathrm{mg} \text { to } 250 \mathrm{mg} \text { just because of its side effect } \\
\text { (bitter taste) }\end{array}$ & Yes \\
\hline $\begin{array}{r}\text { In the presence of Piroxicam-beta-cyclodextrin, there was no need to give Diclofenac } \\
\text { Sodium. So, only one was dispensed. }\end{array}$ & Yes \\
\hline Dose correction of vancomycin in renal compromised patient & Yes \\
\hline Adjustment of rate of infusion of drug causing adverse consequences & Yes \\
\hline $\begin{array}{r}\text { Tablet Augmentin } 625 \mathrm{mg} \text { was recommended to } 10 \text { year old child. Instead of tablet, } \\
\text { syrup was dispensed. }\end{array}$ & $\begin{array}{l}\text { Yes } \\
\text { Reason: Dose seemed to be high for child. }\end{array}$ \\
\hline
\end{tabular}


Good working relationships between all healthcare professionals are essential to the delivery of personalized and effective patient services. All health professions must show greater responsiveness to changing patient needs (Debbie, 2010). According to data collected from this survey Pharmacists believed that only $49 \%$ of Physicians and $44 \%$ of Nurses appreciated the interventions made by them where as $51 \%$ of Physicians and $56 \%$ of nurses did not like their involvement. The possible reason for this on behalf of physician may be that they do not like any involvement in decisions made by them they take it to their ego and Nurses do not like Pharmacist interventions may be due to their fear that they might lose their worth (figure 2).

In general, most of the Pharmacists had knowledge about DRPs, other related terms and also about reporting but most of them did not actively participate to reduce incidences of DRPs because of lack of their acceptance by society and other health care professionals.

\section{CONCLUSION AND RECOMMENDATIONS}

A Drug-Related Problem is an event or circumstance involving drug therapy that actually or potentially interferes with desired health outcomes. There are many preventable DRPs existing in our health care settings which could be reduced by pharmacist intervention. It was concluded that most of the Pharmacists had knowledge about DRPs, other related terms and also about reporting but most of them did not actively participate to reduce incidences of DRPs because of lack of their acceptance by society and other health care professionals, lack of proper reporting system, lack of incentives and lack of time due to managerial job structure specially in case of retail pharmacy setup.

\section{Recommendations:}

$>$ Pharmacists should actively participate and intervene to reduce the incidence of DRPs despite the discouraging behavior of other health care professionals, to prove their worth.

$>$ Pharmacists should keep their "clinical knowledge" up to date for making interventions to reduce the incidence of DRPs.

$>$ There should be a proper DRP reporting system in Hospitals and other health care settings.

$>$ The hospital committees should encourage the pharmacists to give their input regarding the medication use in the hospitals.

$>$ Pharmacist should be trained to recognize the risk factors of DRPs, as well as to design strategies to reduce their incidence.

$>$ Pharmacist should be encouraged to do patient education and patient counseling, so that the incidence of DRPs could be prevented and reduced effectively.

\section{ACKNOWLEDGEMENT}

We express gratitude to our Director of Institute, Prof. Dr. Maqsood Ahmad, for his kind guidance. We also express profound appreciation to our honorable teachers for their thoughtful guidance and sagacious advices. We are greatly indebted to our parents for their continuous support, encouragement and supplications at all stages.

\section{REFERENCES}

Abbott, R. D., Bogden, P. E., Koontz, L. M., Onopa, J. K. and Williamson, P. (1998) Comparing standard care with a physician and pharmacist team approach for uncontrolled hypertension. J Gen Intern Med, Volume 13, Pages 740-45. [DOI]

Allen, K. M., Bright, J., Carey, D. L., Doecke, C. J., Dooley, M. J., Galbraith, K. J., and Taylor, G. R. (2004) Prospective multicentre study of pharmacist initiated changes to drug therapy and patient management in acute care government funded hospitals. Br J Clin Pharmacol, Volume 57, 2004, Pages 513-21. [DOI]

Anne, L. (2005). Adverse drug reactions, (2nd ed.), Pharmaceutical Press, ISBN 9780853696018.

Antoine, C. G. E., Marie, L.and Ronald, H. B. M., (2000). An ABC of DrugRelated Problems, Drug Safety, Volume 22, Pages 415-23. [DOI]

Aronson, J. K. andEdwards, I. R. (2000) Adverse drug reactions: definitions, diagnosis, and Management.Lancet, Volume 356, Pages 1255-59. [DOI]

Arshad, Y. K., Nousheen, A. and Rabia, B. (2011) Food-Drug Interactions. Oman Med J, Volume26, Pages 77-83. [DOI]

Bates, D. W., Brown, B. A., Cotugno, M. C., Horng, M., Kachalia, A., Kirwin, J. L., McKean, S. C.,Roy, C. L., Schnipper, J. L., Tarvin, E. and Wahlstrom, S. A.(2006) Role of pharmacist counseling in preventing adverse drug events after hospitalization. Arch Intern Med, Volume 166, Pages 565-71. [DOI]

Bindoff, I. K., Peterson, G. M., Tenni, P. C. and Williams, M. (2012) A clinical knowledge measurement tool to assess the ability of community pharmacists to detect drug-related problems. Int. J. Pharm Pract, Volume 20, Pages 238-48. [DOI]

Bird, J. A. and Lipton, H. L. (1994) The impact of clinical pharmacist's consultations on geriatric patient's compliance and medical care use: a randomized controlled trial. Gerontologist, Volume 34, Pages 307-15. [DOI]

Bond, C. A. and Raehl, C. L.(2006) Clinical pharmacy services, pharmacy staffing and adverse drug reactions in United States hospitals. Pharmacotherapy, Volume 26, Pages 735-47. [DOI]

Bren, L. (2001) Frances Oldham Kelsey: FDA medical reviewer leaves her mark on history. FDA Consumer, Volume 35, Pages 24-9.

Carlyn, V. S., Rosemin, K., and Simon, P. A. (2008) Informed shared decision making: An exploratory study in pharmacy. Pharm Pract (Granada), Volume 6, Pages 57-67. [Link]

Charles, D. H. and Linda, M. S. (1990) Opportunity and responsibilities in Pharmaceutical care. AM J Hosp Pharm, Volume 47, Pages 533-43.

Chris, D., Dennis, F., Shanthi, N., Sten, O., et al. (2013) WHO Strategy for Collecting Safety Data in Public Health Programmes: Complementing Spontaneous Reporting Systems. Drug Saf, Volume 36, Pages 75-81. [DOI]

Christine, H. (2013). Adverse Drug Reactions: A Study in Policy Implementation.

Debbie, R. (2010) Collaboration between doctors and pharmacists in the community. Aust Prescr, Volume 33, Pages 191-193. [Link]

Donovan, J. L., Drake, J. A., Tran, M. T.and Whittaker, P. (2006) Pharmacymanaged anticoagulation: assessment of in-hospital efficacy and evaluation of financial impact and community Acceptance. J Thromb Thrombolysis, Volume 22, Pages 23-30. [DOI]

Fatimah, B. M. K., Shu, C. L. and Yvonne, K.(2005) Drug-related problems in hospitalized patients on polypharmacy: the influence of age and gender.TherClin Risk Manag, Volume 1, Pages 39-48. [DOI]

Foppe, V. M. (2005) Drug-related problems: a cornerstone for pharmaceutical care. Journal of the Malta College of Pharmacy Practice, Volume 10, Pages 5-8. [Link]

Grootheest, A. C. and Harmark, L. (2008) Pharmacovigilance: methods, recent developments and future perspectives. Eur J Clin Pharmacol, Volume 64, Pages 743-752. [DOI]

Hanlon, J. T., Weinberger, M., Samsa, G. P., Schmader, K. E., et al. (1996) A randomized, controlled trial of a clinical pharmacist intervention to improve inappropriate prescribing in elderly outpatients with polypharmacy. Am. J. Med., Volume 100, Pages 428-37. [DOI]

Hege, S. B., (2007) Drug-related problems in hospitalised patients ([Link] [Accessed on: May, 2014]

Hege, S. B. and Kirsten, K. V. (2008) The Impact of Clinical Pharmacists on Drug-Related Problems and Clinical Outcomes, Nordic Pharmacological Society. Basic \& Clinical Pharmacology \& Toxicology, Volume 102, Pages 275-280. [DOI]

Hege, S. B., Kirsten, K. V. and Sabine, R. (2007) Classification of drugrelated problems. Journal of the Norwegian Medical Association, Volume 127, Pages 3073-76. PMID:18049498 
Hoffmann, R. J.Rich, M. L. and Ritterhoff, R. J. (1950) A fatal case of aplastic anemia following Chloramphenicol (Chloromycetin) therapy. Ann Intern Med, Volume 33, Pages 1459-67. [DOI]

Janet, M. C., Linda, T. K.and Molla, S. D. (2000). To Err Is Human: Building a Safer Health System, Errors in health care: A leading cause of death and injury. (pp. 27). National Academies Press.

Katzenstein, M.and Mellin, G. W. (1962) The saga of thalidomide, Neuropathy to embryopathy, with case reports of congenital anomalies. N Engl J Med, Volume 267, Pages 1238-44. [DOI]

Linda, M. S., Peter, C. M., Robert, J. C., Ruthanne, R., et al. (1990) Drug Related Problems: Their Structure and Function. DCIP Annals of Pharmacotherapy, Volume 24, Pages 1093- 97. [PMID: 2275235]
PCNE: [Link] [Accessed on: May, 2014].

PCNE: [Link] [Accessed on: May, 2014].

Richard, P. K. (1990) The clinical role of the community pharmacist, Office of the Inspector General, Washington DC: US Department of Health and Human Services.

Requirements for adverse reaction reporting. Geneva. Switzerland: World Health Organization; 1975.

Ulrika, G. (2012) Effects of Clinical Pharmacists Interventions on Drugrelated Hospitalization and appropriateness of Prescribing in Elderly patients. Digitala Vetenskapliga Arkivet, Volume 154, Page 58. 


\section{ANNEXURE - I \\ Pharmacist's Interventions in Reducing the Incidences of DRPs in any Practice Setting Lahore College for Women University}

(Institute of Pharmacy)

\section{DATA COLLECTION FORM}

Date:

Work Place:

Pharmacist: Department:

Job Experience:

1: Knowledge about DRPs (Drug related Problem):
A) Yes
B) $\mathrm{No}$

2: Knowledge about Pharmaceutical Care:
A) Yes
B) $\mathrm{No}$

3: Knowledge about ADR (Adverse Drug Reaction) reporting:
A) Yes
B) $\mathrm{No}$

4: Did you ever identify any "untreated indication" in patients?
A) Yes
B) $\mathrm{No}$

5: Did you ever notice any "improper drug selection" by the prescriber?
A) Yes
B) No

6: Have you ever observed any "sub therapeutic dosage" prescribed to patient?
A) Yes
B) No

7: Have you ever noticed any case in which the patient "failed to receive the drug"?
A) Yes
B) $\mathrm{No}$

8: Have you ever observed any case of "over dosage"?
A) Yes
B) $\mathrm{No}$

9: Have you ever noticed any medical problem that was a result of an ADR?
A) Yes
B) $\mathrm{No}$

10: Did you ever observe any type of "Drug interaction"?
A) Drug-drug interaction
B) Drug-Laboratory interaction
D) None

C) Drug-Food interaction.

11: Have you ever noticed any case of drug use without valid indication?
A) Yes
B) $\mathrm{No}$

12: If any of the noticed DRP (Drug Related Problem), was ever reported?
A) Yes
B) $\mathrm{No}$

If yes, to whom it was reported?

13: Does pharmacist work in collaboration with physicians or other healthcare providers at your workplace/in general?
A) Yes
B) $\mathrm{No}$

14: Any intervention to reduce incidence of DRP by you (Pharmacist)?
A) Yes
B) $\mathrm{No}$

If yes, what was that?

15: Was the intervention accepted?
A) Yes
B) $\mathrm{No}$

Reason:

16: Appreciation of pharmacist's interventions according to other healthcare professionals Physicians:
A) Appreciable
B) Not appreciable

Nurse:
A) Appreciable
B) Not appreciable 
ANNEXURE - II

$\underline{\text { The Basic Classification }}$

\begin{tabular}{|c|c|c|}
\hline & $\begin{array}{l}\text { Code } \\
\text { V6.2 }\end{array}$ & Primary domains \\
\hline Problems & $\begin{array}{l}\text { P2 } \\
\text { P3 } \\
\text { P4 }\end{array}$ & $\begin{array}{l}\text { Treatment effectiveness } \\
\text { There is a (potential) problem with the (lack of) effect of } \\
\text { the pharmacotherapy } \\
\text { Adverse reactions } \\
\text { Patient suffers, or will possibly suffer, from an adverse } \\
\text { drug event } \\
\text { Treatment costs } \\
\text { The drug treatment is more expensive than necessary } \\
\text { Others }\end{array}$ \\
\hline Causes & $\begin{array}{l}\mathrm{C} 4 \\
\mathrm{C} 5\end{array}$ & $\begin{array}{l}\text { Drug selection } \\
\text { The cause of the DRP can be related to the selection of } \\
\text { the drug } \\
\text { Drug form } \\
\text { The cause of the DRP is related to the selection of the } \\
\text { drug form } \\
\text { Dose selection } \\
\text { The cause of the DRP can be related to the selection of } \\
\text { the dosage schedule } \\
\text { Treatment duration } \\
\text { The cause of the DRP is related to the duration of therapy } \\
\text { Drug use/administration process } \\
\text { The cause of the DRP can be related to the way the } \\
\text { patient uses the drug or gets the drug administered, in } \\
\text { spite of proper instructions (on the label, package or } \\
\text { leaflet) } \\
\text { Logistics } \\
\text { The cause of the DRP can be related to the logistics of } \\
\text { the prescribing and dispensing process } \\
\text { Patient } \\
\text { The cause of the DRP can be related to the personality or } \\
\text { behaviour of the patient. } \\
\text { Other }\end{array}$ \\
\hline Interventions & $\begin{array}{l}10 \\
11 \\
12 \\
13 \\
14\end{array}$ & $\begin{array}{l}\text { No intervention } \\
\text { At prescriber level } \\
\text { At patient (or carer) level } \\
\text { At drug level } \\
\text { Other } \\
\end{array}$ \\
\hline Outcome of intervention & $\begin{array}{l}\text { O0 } \\
\text { O1 } \\
\text { O2 } \\
\text { O3 }\end{array}$ & $\begin{array}{l}\text { Outcome intervention unknown } \\
\text { Problem totally solved } \\
\text { Problem partially solved } \\
\text { Problem not solved }\end{array}$ \\
\hline
\end{tabular}

